\title{
Nonlinear relationship between sleep duration and non-suicidal self-injurious behaviour among Chinese adolescents
}

Ying Tang ${ }^{1,2,3,4+}$, Yuhui Wan ${ }^{1,3,4 \dagger}$, Shaojun $\mathrm{Xu}^{1,4}$, Shichen Zhang ${ }^{1,2}$, Jiahu Hao ${ }^{1,2,4}$ and Fangbiao Tao ${ }^{1,2,3,4^{*}}$ (D)

\begin{abstract}
Background: Previous studies have shown a positive association between sleep deprivation and non-suicidal selfinjury (NSSI) among adolescents, but few studies have described the effects of oversleeping and weekend catch-up sleep on NSSI. The present study aimed to explore the nonlinear relationship between sleep duration and NSSI among Chinese adolescents.

Methods: Data from China's National Adolescent Health Surveillance for the years 2014 to 2015 were collected from 15,713 students located across four provinces in China. A self-report questionnaire was used to assess sleep duration and 12-month NSSI. Binomial logistic regression models were used to examine the association between NSSI and sleep duration. The locally estimated scatter plot smoothing (LOESS) method was used to explore the associations of total NSSI number with sleep duration, and binomial regression analysis was used to test this relationship.
\end{abstract}

Results: About $68.5 \%$ of adolescents reported sleeping less than $8 \mathrm{~h}$ on weeknights, while $37.8 \%$ of adolescents slept more than $10 \mathrm{~h}$ per night during weekends. The 12-month prevalence rate of NSSI was $29.4 \%$. Compared to adolescents who reported weekend catch-up sleep of $0-1 \mathrm{~h}$, those who slept $<0 \mathrm{~h}$ (adjusted odds ratio $[a \mathrm{O} R]=$ 1.38, 95\% Confidence Interval [95\% Cl]: 1.16-1.64) had a higher risk of NSSI. Males who reported $\geq 3 \mathrm{~h}$ of weekend catch-up sleep had significantly increased odds of NSSI ( $a \mathrm{OR}=1.20,95 \% \mathrm{Cl}$ : 1.01-1.42). Notably, a positive U-shaped association was observed between the sleep duration and the total NSSI number.

Conclusions: The findings reveal a nonlinear relationship between sleep duration and NSSI among Chinese adolescents. Therefore, it is necessary to be vigilant and screen for sleep duration among adolescents in NSSI treatment or prevention.

Keywords: Sleep duration, Non-suicidal self-injury, Adolescents, Students

\footnotetext{
* Correspondence: taofangbiao@126.com

${ }^{\dagger}$ Ying Tang and Yuhui Wan contributed equally to this work and should be considered co-first authors.

'Department of Maternal, Child and Adolescent Health, School of Public

Health, Anhui Medical University, No 81 Meishan Road, Hefei 230032, Anhui, China

${ }^{2}$ MOE Key Laboratory of Population Health Across Life Cycle, No 81 Meishan Road, Hefei 230032, Anhui, China

Full list of author information is available at the end of the article
}

(c) The Author(s). 2021 Open Access This article is licensed under a Creative Commons Attribution 4.0 International License, which permits use, sharing, adaptation, distribution and reproduction in any medium or format, as long as you give appropriate credit to the original author(s) and the source, provide a link to the Creative Commons licence, and indicate if changes were made. The images or other third party material in this article are included in the article's Creative Commons. licence, unless indicated otherwise in a credit line to the material. If material is not included in the article's Creative Commons licence and your intended use is not permitted by statutory regulation or exceeds the permitted use, you will need to obtain permission directly from the copyright holder. To view a copy of this licence, visit http://creativecommons.org/licenses/by/4.0/ The Creative Commons Public Domain Dedication waiver (http://creativecommons.org/publicdomain/zero/1.0/) applies to the data made available in this article, unless otherwise stated in a credit line to the data. 


\section{Background}

Non-suicidal self-injury (NSSI) is defined as the direct, deliberate destruction of one's own body tissue without suicidal intent [1]. NSSI is a significant global public health issue among adolescents with high prevalence rates [2]. Previous results demonstrate that the rates of NSSI in youth significantly vary between countries as well as across different cities and districts within a country [3-5]. Worldwide, the average 12-month prevalence of NSSI is $19.0 \%$ [6]. In China, the average 6-24 months prevalence of NSSI was $23.3 \%$ [7]. NSSI leads to both physical and social-emotional harm in the short and long term, and may be a gateway for suicide, as NSSI is associated with both an increased desire and capability for suicide [8]. Given the consequences of NSSI and suicide on both society and individuals, accurate identification of the risk factors associated with NSSI is critical.

Adequate sleep is necessary for both physical and mental health among adolescents. However, sleep deprivation is prevalent in modern society [9]. The National Sleep Foundation observed that approximately $61 \%$ of American adolescents aged 13-18 years reported sleeping less than the recommended $8-10 \mathrm{~h}$ of sleep [10-12]. In a survey of 585 adolescents from a high school in China, the vast majority of students (over 93\%) slept less than $8 \mathrm{~h}$ during weeknights, with over $42 \%$ sleeping less than $6.5 \mathrm{~h} \mathrm{[13].} \mathrm{In} \mathrm{another} \mathrm{study,} \mathrm{approxi-}$ mately $51.0 \%$ of 4801 Chinese adolescents (aged 11-20 years) received less than $8 \mathrm{~h}$ of sleep during weeknights [14]. Adolescence is a period characterized by dramatic changes in cognitive, behavioral, social, and emotional functioning [15]. The onset of adolescence has also been characterized by changes in sleep/wake patterns. Both sleep/wake pattern changes and changes to the sleeppressure system (sleep homeostasis) during adolescence favor later timing of sleep [16]. These changes, combined with prevailing social pressures, are responsible for most teenagers sleeping too late and too little [16].

Studies have shown that while school schedules require adolescents to be fully awake early in the morning, reduced parental control over bedtime, sleep hygiene such as caffeine consumption, high levels of social media use, and other behavioral patterns often shape adolescent lifestyles toward predominantly nighttime behavior [17-19]. This interaction leads to chronic patterns of sleep deprivation, a tendency for higher rates of daytime sleepiness, and accumulation of sleep debt during the school week [20]. Adolescents typically attempt to oversleep on non-school days to compensate their sleep debt, especially by sleeping on weekend mornings [20]. In a survey of 9567 secondary school students in New Zealand, the bedtime and rise times during weekdays were 22:17 and 06:57; on the weekend, their bedtime and rise times were 00:09 and 09:31 [21]. In another study, Lee et al. found that the mean sleep duration of 3785 middle and high school students in Korea was $7 \mathrm{~h}$ on weekdays, $8.9 \mathrm{~h}$ on weekends, and $1.8 \mathrm{~h}$ for weekend catch-up sleep [22]. A survey of 1629 Chinese adolescents (aged 12 to 19 years) showed that the average bedtime on school nights was 23:24 and total sleep time was $7.3 \mathrm{~h}$. During weekends, the average bedtime and rise time were delayed by $64 \mathrm{~min}$ and $195 \mathrm{~min}$, respectively [23]. This phenomenon of short, early sleep on weekdays and later, longer sleep on weekends has been called weekend sleep lag or social jet lag [24, 25].

Inadequate sleep duration, sleepiness, and irregular sleep patterns may lead to poor academic performance, psychological symptoms such as depression, and physical health problems such as headaches, obesity and cardiometabolic dysfunction [26]. The effect of sleep patterns on risk-taking behaviors has also been a cause of concern in recent years. Several reports have suggested that sleep duration is associated with the NSSI in adolescents. In a study of Swedish adolescents, poor sleep was associated with NSSI among girls, but not among boys [27]. In a study of Norwegian adolescents, insomnia, short sleep duration, long sleep onset latency, wake after sleep onset, and large differences between weekdays versus weekends bedtimes yielded higher odds of self-harm consistent with a dose-response relationship [28]. Previous studies have focused on sleep quality and inadequate sleep duration on NSSI; however, few studies have focused on oversleeping and weekend catch-up sleep [29, 30]. To date, there has been no evidence of a U-shaped relationship between sleep duration and NSSI.

A previous study showed that adolescents with psychological symptoms are at an elevated risk of developing NSSI [31]. In addition, insufficient sleep in adolescents can be affected by excessive screen time use, with insufficient sleep in adolescents having been linked to suicidal ideation/NSSI [32-34]. Therefore, in this study, we aimed to explore the nonlinear relationship between sleep duration and NSSI among Chinese adolescents, considering the influence of sleep quality, psychological symptoms and screen time. We hope that this study will help us provide relevant strategies to support adolescent NSSI prevention.

\section{Methods \\ Participants}

The data were obtained from China's National Adolescent Health Surveillance from 2014 to 2015. This is an annual school-based surveillance system involving adolescents and young adults from the same junior and senior high schools located in Xinxiang (central), Yangjiang (south), Chongqing (west) and Shenyang (north) areas. These areas are broadly representative of the average population within China in terms of 
economic development and demographic composition. Eight schools (2 junior and 2 senior high schools from urban and rural, respectively) in each geographic region were randomly selected.

A total sample of 15,713 students from grade 7-12 were invited to participate in the study. Of these students, 1037 (6.6\%) were excluded from the study because of (1) absence from school on the day of the survey or unwillingness to respond to the questionnaire, (2) missing data through fictitious or inconsistent responses. Finally, we received 14,676 (93.4\%) effective questionnaires, including 7017 males (47.8\%) and 7377 junior school students (50.3\%). The students aged from 10 to 24 years (mean 15.20, SD 1.75). In addition, the participants of four regions were 3968 (Xinxiang), 3539 (Yangjiang), 4007 (Chongqing), and 3162 (Shenyang), respectively.

\section{Procedure}

The study ensured that all the participants and their guardians were aware of the purpose and content of this investigation. The students who agreed to participate in the survey stayed in the classroom, while those who did not were permitted to leave. Each center used an anonymous, self-reported questionnaire. The completion of the questionnaire took approximately $25 \mathrm{~min}$. A teacher was present in the classroom, but was unable to observe student responses. The investigators checked the accuracy and completeness of the returned questionnaires and removed the unqualified questionnaires. Informed consent was obtained from the parents/ guardians of each student prior to the completion of questionnaires. Approval for the design and data collection procedures was obtained by the Ethics Committee of Anhui Medical University. Detailed survey information can be found in our previous article [35].

\section{Measures \\ Socio-demographic information}

A self-report questionnaire was used to collect sociodemographic information, including sex (male or female), grade (junior or senior level in middle school), urban/ rural residency, household structure (only child or more than one child), parents' education level (completion of junior middle school, senior middle school, college, etc.) and self-perceived family economic status (poor, general or good). The additional file provided a questionnaire (Additional File 1).

\section{Psychological symptoms and screen time}

Psychological symptoms, including emotional symptoms (depression and anxiety symptoms, e.g., 'Do you always feel distressed?'), behavioural symptoms (paranoid and hostile behaviors, e.g., 'Do you always have the impulse to damage something?') and social adaptation symptoms (bad relationships with family and friends, e.g., 'Could you not fit well into school life?'), were evaluated using the psychological domain of the Multidimensional Subhealth Questionnaire of Adolescents (MSQA) [31]. The MSQA has been widely used in mainland China and has been reported by various groups to be a valid and reliable method to explore the current state of psychological health in adolescents $[36,37]$. Cronbach's alpha for the MSQA was 0.951 in the present study.

Screen time was measured by video watching and video game playing times. The subjects reported screen time using the following questions: "On an average school day, for how many hours do you watch videos (such as watching TV, mobile phone, MP4, DVD/ VCD)?" and "On an average school day, for how many hours do you play video games (such as game consoles, computer games, mobile games)?”. A similar question was used to define the average screen time on weekends [38]. All of these questions have seven answer categories: '0 h', ‘ $\leq 0.5$ h', '0.5-1 h', ' $1-2$ h', ' $2-4$ h', ' $4-6$ h', and '>6 h'.

\section{Sleep variables}

The survey contained two questions concerning sleep duration [35]. The first question represented the usual weekday sleep duration: "In the last month, how many hours of actual sleep did you usually get at night on weekdays?" A similar question was used to define the usual weekend sleep duration. Daily sleep duration was calculated as a weighted average of weekday and weekend sleep durations using the following formula: ([ \{usual weekday sleep duration $\} \times 5]+[\{$ usual weekend sleep duration $\} \times 2]) / 7$. Weekend catch-up sleep was calculated using the formula: ([usual weekend sleep duration]-[usual weekday sleep duration]). For the purpose of statistical analyses in the present study, sleep duration was divided into 6 categories: '< 6 h', ' $6-7$ h', ' $7-8$ h', ' 8 9 h', '9-10 h', and ' $\geq 10 \mathrm{~h}$ '. Weekend catch-up sleep was divided into 5 categories: '< 0 h', '0-1 h', ' $1-2$ h', ' $2-3$ h', and ' $\geq 3 \mathrm{~h}$ '. Sleep quality was ascertained from responses on a 4-point Likert scale to the question "In the past month, what did you think of your sleep quality?" Response options were very good, good, poor, and very poor [35].

\section{NSSI}

NSSI was assessed using the following question: 'In the past 12 months, have you ever harmed yourself in a way that was deliberate, but not intended to take your life?' Eight NSSI behaviors were presented, and the details of the questions were as follows: (1) Have you ever hit yourself?; (2) Have you ever pulled your hair yourself?; (3) Have you ever banged your head or fist against something?; (4) Have you ever pinched or scratched 
yourself?; (5) Have you ever bitten yourself?; (6) Have you ever cut or pierced yourself?; (7) Have you ever deliberately taken an overdose (e.g. of drugs, alcohol or smoking)?; and (8) Have you ever ingested a toxic substance or object? For those who confirmed that they had engaged in NSSI, the frequency of NSSI was investigated [31]. In this study, for statistical analysis purposes, NSSI was analyzed in two different ways. Frequency of selfharm was coded as follows: (a) 2 groups: 'NSSI' (one or more times), and Non-NSSI (none); and (b) continuous variable: 'Total number of self-injuries' (sum of the eight types of frequency of self-harm). In the present study, the Cronbach's alpha coefficient for the NSSI was 0.798 .

\section{Statistical analysis}

Statistical analyses were carried out using SPSS version 24.0, and R software version 3.6.1. Means and standard deviations of sleep duration were calculated separately for each sex group as well as for each grade group of participants. For comparisons between sex and grade groups, independent $t$-tests were conducted for sleep duration, and effect sizes were calculated. The frequencies and percentages of NSSI in the different groups were calculated. Pearson's chi-squared test was used to examine differences in sex, grade, sleep duration and other variables between adolescents who reported NSSI and those who did not, and effect sizes were calculated. Univariate logistic regression analysis was used to examine the associations between covariates (e.g., sex, sleep duration, etc.) with NSSI. Binomial logistic regression models were used to examine the associations of NSSI with daily sleep duration, weekday sleep duration, weekend sleep duration and weekend catch-up sleep, by adjusting for sociodemographic variables, etc. Sex and grade differences in these associations were examined. The locally estimated scatter plot smoothing (LOESS) method was used to explore the associations of total NSSI number with daily sleep duration, weekday sleep duration, weekend sleep duration and weekend catch-up sleep. This method was especially useful for representing the nonlinear relationship between variables, for example, the U-shaped relation. GetData Graph Digitizer version 2.26 was used to find the nadir point. Binomial regression analysis was used to test the relationship between total NSSI number and sleep duration by adjusting for sociodemographic variables, sleep quality, psychological symptoms, and screen time. The level of significance was set at $P<0.05$.

\section{Results}

\section{Comparisons of sleep duration between sex and grade} groups

The usual daily sleep duration of adolescents (the total group) was $7.6 \mathrm{~h}$ and the mean sleep duration was $7 \mathrm{~h}$ on weekdays, $9 \mathrm{~h}$ on weekends, and $1.9 \mathrm{~h}$ for weekend catch-up sleep. Males had longer weekday sleep durations than females did, while females had longer weekend sleep durations and weekend catchup sleep than males did. Junior middle school students slept significantly longer than senior middle school students on both weekdays and weekends, and had less weekend catch-up sleep than senior middle school students did $(P<0.001$ for each, see Table 1$)$. The percentage of adolescents who slept $<8 \mathrm{~h}$ per night during weeknights was $68.5 \%$, and the percentage of adolescents who slept $\geq 10 \mathrm{~h}$ per night during weekends was $37.8 \%$ for the total group (see Table 2). In this survey, about $63.5 \%$ of males and $73.1 \%$ of females reported sleeping for less than $8 \mathrm{~h}$ on weeknights. Approximately $49.6 \%$ of junior middle school students and $87.6 \%$ of senior middle school students reported sleeping for less than $8 \mathrm{~h}$ on weeknights.

\section{The prevalence rates and characteristics of NSSI}

The 12-month prevalence rate of NSSI was $29.4 \%$. Of all the self-injuries disclosed, the type of NSSI most reported included banging head/ fisting against the subject (18.4\%), hitting (13.8\%) and pinching/scratching (11.1\%). A significant difference was found in the distribution of NSSI by most sample characteristics, including regional areas, sex, grade, household structure, parents' education level, self-perceived family economic status, sleep quality, psychological symptoms and screen time $(P<0.05)$, while NSSI revealed no statistically significant differences by urban/rural residency $(P>0.05)$. In addition, there was a marked difference between sleep duration and catch-up sleep with NSSI $(P<0.001$, see Table 2$)$.

\section{Univariate logistic regression analyses}

Univariate logistic regression analyses showed that the regional areas (crude odds ratios $[O R s]=0.83,95 \%$ Confidence Interval $[95 \% C I]: 0.76-0.92)$, sex $(O R s=1.24$, 95\%CI: $1.16-1.33)$, grade (ORs $=1.19,95 \% C I: 1.11-1.28)$, only child $(O R s=1.10,95 \% C I$ : $1.02-1.18)$, mother's education level $(O R s=1.15, \quad 95 \% C I: \quad 1.01-1.32)$, selfperceived family economic status $(O R s=1.35,95 \% \mathrm{CI}$ : $1.18-1.54$ ), sleep quality (ORs $=0.36,95 \% C I: 0.31-0.41$ ), psychological symptoms (ORs $=3.17,95 \% C I$ : 2.93-3.42), weekday video time $(O R s=1.10,95 \% C I: 1.07-1.12)$, weekend video time (ORs $=1.13,95 \% C I$ : 1.11-1.15), weekday video game time (ORs $=1.07,95 \% C I$ : $1.04-1.09)$ and weekend video game time (ORs $=1.10,95 \% C I: 1.08$ 1.12) were significantly associated with NSSI. Urban/ rural residency and father's education level were not significantly associated with NSSI. 
Table 1 Comparisons of sleep duration between sex and grade groups

\begin{tabular}{|c|c|c|c|c|}
\hline Variables & $\begin{array}{l}\text { Daily sleep } \\
\text { duration(h) }\end{array}$ & $\begin{array}{l}\text { Weekday sleep } \\
\text { duration(h) }\end{array}$ & $\begin{array}{l}\text { Weekend sleep } \\
\text { duration(h) }\end{array}$ & $\begin{array}{l}\text { Weekend catch-up } \\
\text { sleep(h) }\end{array}$ \\
\hline \multicolumn{5}{|l|}{ Sex } \\
\hline Male $(n=7017)$ & $7.64 \pm 1.12$ & $7.15 \pm 1.26$ & $8.87 \pm 1.72$ & $1.72 \pm 1.86$ \\
\hline Female $(n=7659)$ & $7.51 \pm 1.01$ & $6.91 \pm 1.13$ & $9.01 \pm 1.57$ & $2.10 \pm 1.70$ \\
\hline$t$ & 7.251 & 11.941 & -5.209 & -12.816 \\
\hline$P$ value & $<0.001^{* *}$ & $<0.001^{* *}$ & $<0.001^{* *}$ & $<0.001^{* *}$ \\
\hline$d$ & 0.129 & 0.212 & -0.089 & -0.224 \\
\hline \multicolumn{5}{|l|}{ Grade } \\
\hline $\begin{array}{l}\text { Junior middle school ( } n= \\
7377)\end{array}$ & $7.95 \pm 1.09$ & $7.50 \pm 1.21$ & $9.08 \pm 1.58$ & $1.59 \pm 1.66$ \\
\hline $\begin{array}{l}\text { Senior middle school }(n= \\
\text { 7299) }\end{array}$ & $7.20 \pm 0.91$ & $6.55 \pm 0.99$ & $8.81 \pm 1.70$ & $2.26 \pm 1.86$ \\
\hline$t$ & 45.460 & 51.745 & 10.169 & -22.953 \\
\hline$P$ value & $<0.001^{* *}$ & $<0.001^{* *}$ & $<0.001^{* *}$ & $<0.001^{* *}$ \\
\hline$d$ & 0.824 & 0.960 & 0.159 & -0.360 \\
\hline Total $(N=14,676)$ & $7.58 \pm 1.07$ & $7.03 \pm 1.20$ & $8.95 \pm 1.64$ & $1.92 \pm 1.79$ \\
\hline
\end{tabular}

${ }^{*} P<0.05$, ${ }^{*} P<0.001$; Statistical methods: independent $t$-tests, $d$ is effect sizes

\section{Associations sleep duration and NSSI and sex/ grade difference}

After adjusting for covariates (variables that were significantly associated with each form of NSSI), multivariable logistic regressions was performed to explore the association between sleep duration and NSSI and sex/grade difference (see Tables 3 and 4). Compared to adolescents who reported $8-9 \mathrm{~h}$ of sleep, those who reported less than $6 \mathrm{~h}$ of sleep duration, including daily sleep duration (adjusted odds ratio $[a O R]=1.42,95 \% C I$ : $1.18-1.71$ ), weekday sleep $(a O R=1.24,95 \% C I: 1.05-1.45)$, and weekend sleep $(a O R=1.55,95 \% C I: 1.20-2.01)$, might have led to higher adjusted odds of NSSI for adolescents. Compared to adolescents who reported weekend catchup sleep of $0-1 \mathrm{~h}$, those who slept $<0 \mathrm{~h}(a O R=1.38$, 95\%CI: 1.16-1.64) had a higher risk of NSSI. Sex and grade differences were found in the effects of sleep duration on NSSI. Males who reported $\geq 3 \mathrm{~h}$ of weekend catch-up sleep had significantly increased odds of NSSI $(a O R=1.20,95 \% C I: 1.01-1.42)$. Senior middle school students who reported $1-2 \mathrm{~h}(a O R=1.24,95 \% C I$ : $1.01-$ $1.52)$ or $2-3 \mathrm{~h}(a O R=1.24,95 \% C I$ : $1.02-1.51)$ of weekend catch-up sleep had significantly increased odds of NSSI. However, this result was not found in females and junior middle school students.

\section{Associations sleep duration and total NSSI number}

Scatterplots fit with a LOESS curve depicting the relationship between sleep duration and total NSSI number were non-linear (Fig. 1). Daily sleep, weekend catch-up sleep, weekday sleep and weekend sleep duration all had a U-shaped relationship with the total NSSI number.
A GetData Graph Digitizer was used to determine the nadir point. The U-shape curve depicting the relationship between daily sleep duration and NSSI had a nadir point of approximately $8.2 \mathrm{~h}$, the weekend catch-up sleep U-shaped curve was seen with a nadir point of approximately $0.9 \mathrm{~h}$, the weekday sleep U-shaped curve was seen with a nadir point of approximately $7.7 \mathrm{~h}$, and the weekend sleep U-shaped curve was seen with a nadir point of approximately $8.2 \mathrm{~h}$.

After adjusting for covariates (regional areas, sex, grade, registered residence, household structure, parents' education level, self-perceived family economic status, sleep quality, psychological symptoms, and screen time), binomial regression was performed to test the association between sleep duration and total NSSI number (see Table 5). The results of the binomial regression analysis showed that a positive U-shaped association was observed between the entire sleep duration and total NSSI number $(P<0.001)$.

\section{Discussion}

The present study examined the relationship between sleep duration and NSSI among adolescents in China. As hypothesized, our research found that both sleep deprivation and oversleeping were associated with an increased risk of NSSI after adjustment for important confounding factors. We believe that this is the first largesample cross-sectional study to report a U-shaped association between sleep duration and total NSSI number.

In this study, we found that sleep deprivation and oversleeping have become increasingly prevalent in China, with $68.5 \%$ of adolescents sleeping $8 \mathrm{~h}$ or fewer 
Table 2 Prevalence of NSSI by sample characteristics

\begin{tabular}{|c|c|c|c|c|c|}
\hline Variables & $\mathrm{N}(\%)$ & NSSI (\%) & Non-NSSI (\%) & $x^{2}$ & $\varphi / V$ \\
\hline Regional areas & & & & $21.170^{* *}$ & $0.038^{* * *}$ \\
\hline YangJiang & $3539(24.1)$ & 1103(31.2) & $2436(68.8)$ & & \\
\hline ShenYang & $3162(21.5)$ & $935(29.6)$ & $2227(70.4)$ & & \\
\hline XinXiang & $3968(27.0)$ & $1060(26.7)$ & 2908(73.3) & & \\
\hline ChongQing & $4007(27.3)$ & $1219(30.4)$ & 2788(69.6) & & \\
\hline Sex & & & & $35.341^{* *}$ & $-0.049^{* *}$ \\
\hline Male & 7017(47.8) & 2228(31.8) & $4789(68.2)$ & & \\
\hline Female & $7659(52.2)$ & 2089(27.3) & $5570(72.7)$ & & \\
\hline Grade & & & & $22.538^{* *}$ & $-0.039^{* *}$ \\
\hline Junior middle school & $7377(50.3)$ & 2301(31.2) & $5076(68.8)$ & & \\
\hline Senior middle school & 7299(49.7) & 2016(27.6) & $5283(72.4)$ & & \\
\hline Urban/rurality & & & & 0.001 & 0.000 \\
\hline Rural & $7493(51.1)$ & $2205(29.4)$ & $5288(70.6)$ & & \\
\hline Urban & $7183(48.9)$ & 2112(29.4) & $5071(70.6)$ & & \\
\hline Only child & & & & $6.727^{*}$ & $-0.021^{*}$ \\
\hline Yes & $6608(45.0)$ & 2015(30.5) & $4593(69.5)$ & & \\
\hline No & $8068(55.0)$ & $2302(28.5)$ & $5766(71.5)$ & & \\
\hline Father's education level & & & & $11.609^{*}$ & $0.028^{*}$ \\
\hline Less than junior middle school & $2158(14.7)$ & $689(31.9)$ & $1469(68.1)$ & & \\
\hline Junior middle school & $6239(42.5)$ & $1840(29.5)$ & $4399(70.5)$ & & \\
\hline Senior middle school & $4256(29.0)$ & 1186(27.9) & $3070(72.1)$ & & \\
\hline College or more & 2023(13.8) & $602(29.8)$ & $1421(70.2)$ & & \\
\hline Mother's education level & & & & $15.825^{*}$ & $0.033^{*}$ \\
\hline Less than junior middle school & 2686(18.3) & $867(32.3)$ & $1819(67.7)$ & & \\
\hline Junior middle school & $6331(43.1)$ & 1854(29.3) & $4477(70.7)$ & & \\
\hline Senior middle school & $4027(27.4)$ & $1119(27.8)$ & $2908(72.2)$ & & \\
\hline College or more & 1632(11.1) & $477(29.2)$ & 1155(70.8) & & \\
\hline Family economic status & & & & $62.899^{* *}$ & $0.065^{* *}$ \\
\hline Poor & 2020(13.8) & $741(36.7)$ & $1279(63.3)$ & & \\
\hline General & $10,860(74.0)$ & $3036(28.0)$ & $7824(72.0)$ & & \\
\hline Good & 1796(12.2) & $540(30.1)$ & $1256(69.9)$ & & \\
\hline Sleep quality & & & & $254.451^{* *}$ & $0.132^{* *}$ \\
\hline Very Good & $2416(16.5)$ & $457(18.9)$ & 1959(81.8) & & \\
\hline Good & $6426(43.8)$ & 1788(27.8) & $4638(72.7)$ & & \\
\hline Poor & $4500(30.7)$ & $1544(34.3)$ & 2956(65.6) & & \\
\hline Very poor & 1334(9.1) & $528(39.6)$ & $806(60.6)$ & & \\
\hline Psychological symptoms & & & & $906.125^{* *}$ & $0.248^{* *}$ \\
\hline Yes & $4027(27.4)$ & 1926(47.8) & $2101(52.2)$ & & \\
\hline No & $10,649(72.6)$ & $2391(22.5)$ & $8258(77.5)$ & & \\
\hline Weekday video time (h) & & & & $74.449^{* *}$ & $0.071^{* *}$ \\
\hline 0 & $6331(43.1)$ & $1701(26.9)$ & $4630(73.1)$ & & \\
\hline$\leq 0.5$ & $3090(21.1)$ & $874(28.3)$ & $2216(71.7)$ & & \\
\hline $0.5-1$ & 2198(15.0) & $696(31.7)$ & $1502(68.3)$ & & \\
\hline $1-2$ & $1387(9.5)$ & $438(31.6)$ & $949(68.4)$ & & \\
\hline
\end{tabular}


Table 2 Prevalence of NSSI by sample characteristics (Continued)

\begin{tabular}{|c|c|c|c|c|c|}
\hline Variables & $N(\%)$ & NSSI (\%) & Non-NSSI (\%) & $x^{2}$ & $\varphi / V$ \\
\hline $2-4$ & $761(5.2)$ & 258(33.9) & $503(66.1)$ & & \\
\hline $4-6$ & $376(2.6)$ & 139(37.0) & $237(63.0)$ & & \\
\hline$>6$ & 533(3.6) & 211(39.6) & $322(60.4)$ & & \\
\hline Weekend video time $(h)$ & & & & $167.631^{* *}$ & $0.107^{* *}$ \\
\hline 0 & 1737(11.8) & $362(20.8)$ & $1375(79.2)$ & & \\
\hline$\leq 0.5$ & 1818(12.4) & $475(26.1)$ & 1343(73.9) & & \\
\hline $0.5-1$ & $2276(15.5)$ & $618(27.2)$ & 1658(72.8) & & \\
\hline $1-2$ & $2601(17.7)$ & $727(28.0)$ & $1874(72.0)$ & & \\
\hline $2-4$ & 2484(16.9) & 784(31.6) & $1700(68.4)$ & & \\
\hline $4-6$ & 1692(11.5) & 574(33.9) & 1118(66.1) & & \\
\hline$>6$ & 2068(14.1) & $777(37.6)$ & $1291(62.4)$ & & \\
\hline Weekday video game time (h) & & & & $32.089^{* *}$ & $0.047^{* *}$ \\
\hline 0 & $8334(56.8)$ & $2347(28.2)$ & $5987(71.8)$ & & \\
\hline$\leq 0.5$ & 2770(18.9) & $817(29.5)$ & 1953(70.5) & & \\
\hline $0.5-1$ & 1486(10.1) & $457(30.8)$ & $1029(69.2)$ & & \\
\hline $1-2$ & $891(6.1)$ & 274(30.8) & $617(69.2)$ & & \\
\hline $2-4$ & $472(3.2)$ & 160(33.9) & $312(66.1)$ & & \\
\hline $4-6$ & 285(1.9) & 93(32.6) & 192(67.4) & & \\
\hline$>6$ & $438(3.0)$ & 169(38.6) & $269(61.4)$ & & \\
\hline Weekend video game time (h) & & & & $123.035^{* *}$ & $0.092^{* *}$ \\
\hline 0 & 2790(19.0) & $698(25.0)$ & 2092(75.0) & & \\
\hline$\leq 0.5$ & 2354(16.0) & $635(27.0)$ & 1719(73.0) & & \\
\hline $0.5-1$ & 2173(14.8) & $560(25.8)$ & 1613(74.2) & & \\
\hline $1-2$ & 2330(15.9) & $671(28.8)$ & 1659(71.2) & & \\
\hline $2-4$ & $1820(12.4)$ & 613(33.7) & $1207(66.3)$ & & \\
\hline $4-6$ & 1392(9.5) & $475(34.1)$ & $917(65.9)$ & & \\
\hline$>6$ & $1817(12.4)$ & $665(36.6)$ & 1152(63.4) & & \\
\hline Daily sleep duration (h) & & & & $55.717^{* *}$ & $0.062^{* *}$ \\
\hline$<6$ & $712(4.9)$ & 284(39.9) & $428(60.1)$ & & \\
\hline $6-7$ & $3343(22.8)$ & 1036(31.0) & $2307(69.0)$ & & \\
\hline $7-8$ & $5771(39.3)$ & 1688(29.2) & 4083(70.8) & & \\
\hline $8-9$ & $3359(22.9)$ & $911(27.1)$ & $2448(72.9)$ & & \\
\hline $9-10$ & $1145(7.8)$ & $309(27.0)$ & $836(73.0)$ & & \\
\hline$\geq 10$ & $346(2.4)$ & $89(25.7)$ & $257(74.3)$ & & \\
\hline Weekday sleep duration (h) & & & & $43.605^{* *}$ & $0.055^{* *}$ \\
\hline$<6$ & $1125(7.7)$ & $413(36.7)$ & $712(63.3)$ & & \\
\hline $6-7$ & 4386(29.9) & 1305(29.8) & $3081(70.2)$ & & \\
\hline $7-8$ & $4546(31.0)$ & $1354(29.8)$ & 3192(70.2) & & \\
\hline $8-9$ & $3182(21.7)$ & $854(26.8)$ & 2328(73.2) & & \\
\hline $9-10$ & 1020(7.0) & $284(27.8)$ & $736(72.2)$ & & \\
\hline$\geq 10$ & $417(2.8)$ & $107(25.7)$ & $310(74.3)$ & & \\
\hline Weekend sleep duration (h) & & & & $49.429^{* *}$ & $0.058^{* *}$ \\
\hline$<6$ & $287(2.0)$ & 130(45.3) & $157(54.7)$ & & \\
\hline $6-7$ & $716(4.9)$ & $244(34.1)$ & $472(65.9)$ & & \\
\hline
\end{tabular}


Table 2 Prevalence of NSSI by sample characteristics (Continued)

\begin{tabular}{|c|c|c|c|c|c|}
\hline Variables & $\mathrm{N}(\%)$ & NSSI (\%) & Non-NSSI (\%) & $x^{2}$ & $\varphi / V$ \\
\hline $7-8$ & 1376(9.4) & $431(31.3)$ & $945(68.7)$ & & \\
\hline $8-9$ & $3729(25.4)$ & 1054(28.3) & 2675(71.7) & & \\
\hline $9-10$ & $3020(20.6)$ & $860(28.5)$ & $2160(71.5)$ & & \\
\hline$\geq 10$ & 5548(37.8) & 1598(28.8) & $3950(71.2)$ & & \\
\hline Weekend catch-up sleep (h) & & & & $59.123^{* *}$ & $0.063^{* *}$ \\
\hline$<0$ & $966(6.6)$ & $365(37.8)$ & $601(62.2)$ & & \\
\hline $0-1$ & 1998(13.6) & $529(26.5)$ & 1469(73.5) & & \\
\hline $1-2$ & $3101(21.1)$ & $825(26.6)$ & 2276(73.4) & & \\
\hline $2-3$ & 4032(27.5) & 1174(29.1) & 2858(70.9) & & \\
\hline$\geq 3$ & 4579(31.2) & $1424(31.1)$ & $3155(68.9)$ & & \\
\hline Total & $14,676(100.0)$ & $4317(29.4)$ & 10,359(70.6) & & \\
\hline
\end{tabular}

${ }^{*} P<0.05,{ }^{* *} P<0.001$; Statistical methods: Chi-square test, $\varphi / V$ is effect sizes. NSSI is non-suicidal self-injury

on school days and $37.8 \%$ of adolescents sleeping $10 \mathrm{~h}$ or more on weekends. Meanwhile, large discrepancies between weekday versus weekend sleep duration was also common among adolescents, and in our study the average weekend catch-up sleep duration of adolescents was $1.9 \mathrm{~h}$. Similar results were obtained in previous studies $[14,22]$. While adolescent changes in the sleep-wake pattern might be explained by their unique physiological characteristics, evidence suggests that sleep patterns in adolescents are influenced by circadian and homeostatic systems, at least in part [39]. The circadian system, a hierarchically organized network of structures responsible for generating approximately $24-\mathrm{h}$ rhythms, is driven in mammals by a circadian pacemaker located in the suprachiasmatic nuclei $(\mathrm{SCN})$ of the hypothalamus [40]. The homeostatic process regulates sleep pressure which accumulates with wake duration and dissipates during subsequent sleep [41]. Previous studies suggest that the sensitivity of the circadian timing system to light exposure may differ in adolescence, favoring a blunted phase advance response to light exposure in the morning and an exaggerated phase-delay response to light exposure in the evening [42]. Evidence also indicates that the internal day length may be longer in adolescents than in adults, thus contributing to phase delay [16]. In addition, melatonin is an important mediator in the circadian system. Adolescents experience a lower amplitude of the daily rhythm of melatonin secretion, which may in turn dampen the signal for sleep [16]. Furthermore, the homeostatic and circadian regulation of sleep is sensitive to gonadal hormones, and these hormones are necessary for the development of a delayed phase during adolescence [39]. These physiological changes may be part of the reason why adolescents sleep too much or too little. However, adolescent sleep is also affected by the psychosocial environment. In a survey of 1101 students aged 13-16 years in Australia, Vernon et al. found that increased nighttime mobile phone use was directly associated with increased occurrences of poor sleep behavior [43]. In another study, Buzek et al. reported a negative association between sleep duration and academic stress among children from families with low socioeconomic status [44]. Most students reported waking up before their natural biological rise time due to early school starting times. In a study of Singaporean female students, a greater increase in sleep duration on school nights and lower levels of subjective sleepiness were reported at 1 month after implementing a 45-min delay in school start times. These positive changes were maintained at 9 months [45]. In the present study, we found that insufficient sleep duration occurred more often among females than males, with approximately $63.5 \%$ of males and $73.1 \%$ of females reported sleeping for less than $8 \mathrm{~h}$ on weeknights. The results obtained in this study are consistent with most other findings [46-48], although some studies have found no sex-related differences in sleep duration [49,50]. Differences across sex in this study could be due to females requiring more preparation time in the morning, and advanced onset of puberty in females may contribute to later bedtimes [48, $51,52]$. The results of the present study also suggests that $49.6 \%$ of junior middle school students and $87.6 \%$ of senior middle school students reported sleeping less than $8 \mathrm{~h}$ on school days. From these results, the difference observed among different grade groups can be partly explained by the following facts: first, bioregulatory pressures sustain evening alertness later into the night with increasing age; second, parental supervision and time spent on sports/physical training largely reduce, academic demands increase, and social networks expand with increasing age, so there is an increased risk for insufficient sleep among senior middle school students [53]. The reasons for variable sleep duration across sex or grade require careful consideration in future 
Table 3 Logistic regression of the effect of sleep duration on NSSI

\begin{tabular}{|c|c|c|}
\hline \multirow[t]{2}{*}{ Variables } & \multicolumn{2}{|l|}{ NSSI } \\
\hline & $\begin{array}{l}\text { Crude OR } \\
(95 \% C l)\end{array}$ & $\begin{array}{l}\text { Adjusted } O R \\
(95 \% C l)\end{array}$ \\
\hline \multicolumn{3}{|c|}{ Daily sleep duration(h) } \\
\hline $8-9$ (ref) & 1.00 & 1.00 \\
\hline$<6$ & $1.78(1.51,2.11)^{* *}$ & $1.42(1.18,1.71)^{* *}$ \\
\hline $6-7$ & $1.21(1.09,1.34)^{* *}$ & $1.14(1.02,1.29){ }^{*}$ \\
\hline $7-8$ & $1.11(1.01,1.22)^{*}$ & $1.09(0.98,1.20)$ \\
\hline $9-10$ & $0.99(0.85,1.16)$ & $1.00(0.85,1.17)$ \\
\hline$\geq 10$ & $0.93(0.72,1.20)$ & $0.93(0.71,1.21)$ \\
\hline \multicolumn{3}{|c|}{ Weekday sleep duration(h) } \\
\hline $8-9$ (ref) & 1.00 & 1.00 \\
\hline$<6$ & $1.58(1.37,1.83)^{* *}$ & $1.24(1.05,1.45)^{*}$ \\
\hline $6-7$ & $1.15(1.04,1.28)^{*}$ & $1.09(0.97,1.23)$ \\
\hline $7-8$ & $1.16(1.05,1.28)^{*}$ & $1.18(1.06,1.31)^{*}$ \\
\hline $9-10$ & $1.05(0.90,1.23)$ & $1.06(0.90,1.25)$ \\
\hline$\geq 10$ & $0.94(0.75,1.19)$ & $0.94(0.74,1.20)$ \\
\hline \multicolumn{3}{|c|}{ Weekend sleep duration(h) } \\
\hline $8-9$ (ref) & 1.00 & 1.00 \\
\hline$<6$ & $2.10(1.65,1.68)^{* *}$ & $1.55(1.20,2.01))^{*}$ \\
\hline $6-7$ & $1.31(1.11,1.56)^{*}$ & $1.15(0.96,1.38)$ \\
\hline $7-8$ & $1.16(1.01,1.32)^{*}$ & $1.13(0.98,1.30)$ \\
\hline $9-10$ & $1.01(0.91,1.12)$ & $1.05(0.93,1.17)$ \\
\hline$\geq 10$ & $1.03(0.94,1.13)$ & $0.96(0.87,1.06)$ \\
\hline \multicolumn{3}{|c|}{ Weekend catch-up sleep(h) } \\
\hline $0-1$ (ref) & 1.00 & 1.00 \\
\hline$<0$ & $1.69(1.43,1.99)^{* *}$ & $1.38(1.16,1.64)^{* *}$ \\
\hline $1-2$ & $1.01(0.89,1.14)$ & $1.02(0.90,1.17)$ \\
\hline $2-3$ & $1.14(1.01,1.29)^{*}$ & $1.11(0.98,1.26)$ \\
\hline$\geq 3$ & $1.25(1.11,1.41)^{* *}$ & $1.08(0.95,1.22)$ \\
\hline
\end{tabular}

${ }^{*} P<0.05$, ${ }^{*} P<0.001$; OR is odds ratios; $\mathrm{Cl}$ is confidence interval; NSSI is non-suicidal self-injury; Adjusted model controlled regional areas, sex, grade, only child, parents' education level, family economic status, sleep quality, psychological symptoms, weekday video time, weekend video time, weekday video game time, weekend video game time

studies, as they may be targets of educational or other interventions.

In recent years, the prevalence rates of NSSI were high and results from the present study showed that the 12month prevalence rate of NSSI was $29.4 \%$. Until now, however, few studies have examined the association between sleep duration and NSSI. Previous studies have shown a close link between sleep problems and selfharm; difficulties initiating sleep, early morning wakening, short sleep duration, severe sleep complaints, daytime sleepiness, and nightmares were associated with an increased risk of self-harm in a dose-dependent manner [28, 29, 54, 55]. In this study, after controlling for potential confounding factors, we found that compared to males who reported weekend catch-up sleep of $0-1 \mathrm{~h}$, males who slept $<0 \mathrm{~h}$ or $\geq 3 \mathrm{~h}$ had a higher risk of NSSI. The results of this study indicate that either excessive or restricted weekend catch-up sleep among males was associated with an increased risk of NSSI. Furthermore, we found that daily sleep, weekend catch-up sleep, weekday sleep, and weekend sleep duration had a U-shape relationship with total NSSI number. However, the underlying mechanism remains unclear. There are several possible explanations for this. It seems plausible that improper sleep duration may disrupt the circadian clock, leading to a subsequent increase in inflammatory biomarkers. In addition, inflammatory markers have been shown to be key markers associated with NSSI. Many studies suggest that the extreme of long sleep duration/ shorter sleep duration or circadian misalignment significantly increased plasma tumor necrosis factor-alpha (TNF- $\alpha$ ), interleukin 10 (IL-10) and C-reactive protein (CRP) [56, 57]. Increased inflammation might change major neurotransmitter metabolism, which subsequently affects frontal function and decreases response inhibition. Additionally, NSSI was related to greater behavioral impulsivity and increased serum TNF- $\alpha$ levels. Therefore, frontal dysfunction associated with greater inflammation might explain the neurobiological basis of NSSI [58]. The hypothalamic-pituitary-adrenal (HPA) axis seems to be a potential mechanism that may explain the link between sleep deprivation and NSSI. Previous findings suggest that total sleep deprivation and chronic circadian misalignment differentially influence cortisol levels. Acute total sleep deprivation increases cortisol levels, whereas circadian misalignment decreases cortisol levels. The current research results are not consistent with the effect of the HPA axis on NSSI. Reichl et al. reported that adolescents engaging in NSSI exhibited significantly higher cortisol awakening responses compared to healthy controls [59]. However, another study showed that the HPA axis is hyporesponsive in adolescents with NSSI. Therefore, reduced secretion of cortisol could play a role in promoting the vulnerability of these individuals to acute stress and maladaptive stress responses [60]. Furthermore, sleep deprivation and NSSI may be linked to reduced connectivity in the default mode network (DMN). Irregular sleep patterns among adolescents are associated with increased path length within the DMN specifically in the right and left lateral parietal lobule, suggesting that sleep regularity may be vital for optimal brain functioning during this developmental period [61]. In addition, reduced DMN connectivity is often observed among adolescents with neuropsychiatric conditions, such as attention-deficit hyperactivity disorder (ADHD), depression, and emerging psychosis [62]. Therefore, sleep irregularity may affect NSSI through alterations in brain connectivity. 
Table 4 Adjusted OR (95\% CI) of NSSI by sex and grade regrading sleep duration

\begin{tabular}{|c|c|c|c|c|}
\hline \multirow[t]{2}{*}{ Variables } & \multicolumn{2}{|c|}{ NSSI [Adjusted OR $(95 \% C l)]$} & \multicolumn{2}{|c|}{ NSSI [Adjusted OR $(95 \% C l)]$} \\
\hline & Female & Male & Junior middle school & Senior middle school \\
\hline \multicolumn{5}{|c|}{ Daily sleep duration(h) } \\
\hline 8-9(ref) & 1.00 & 1.00 & 1.00 & 1.00 \\
\hline$<6$ & $1.48(1.13,1.93) *$ & $1.38(1.07,1.78))^{*}$ & $1.55(1.15,2.09)^{*}$ & $1.30(1.01,1.67)^{*}$ \\
\hline $6-7$ & $1.19(1.01,1.41)^{*}$ & $1.10(0.94,1.30)$ & $1.04(0.87,1.23)$ & $1.13(0.94,1.35)$ \\
\hline $7-8$ & $1.09(0.94,1.27)$ & $1.08(0.94,1.25)$ & $1.12(0.98,1.27)$ & $1.00(0.84,1.19)$ \\
\hline $9-10$ & $1.02(0.81,1.29)$ & $0.99(0.80,1.22)$ & $1.06(0.89,1.26)$ & $0.80(0.51,1.26)$ \\
\hline$\geq 10$ & $1.10(0.72,1.70)$ & $0.85(0.61,1.19)$ & $1.00(0.75,1.36)$ & $0.78(0.44,1.38)$ \\
\hline \multicolumn{5}{|c|}{ Weekday sleep duration(h) } \\
\hline 8-9(ref) & 1.00 & 1.00 & 1.00 & 1.00 \\
\hline$<6$ & $1.34(1.07,1.69)^{*}$ & $1.13(0.90,1.43)$ & $1.20(0.92,1.55)$ & $1.28(1.01,1.62)^{*}$ \\
\hline $6-7$ & $1.18(0.99,1.39)$ & $1.03(0.88,1.21)$ & $0.99(0.85,1.16)$ & $1.16(0.96,1.41)$ \\
\hline $7-8$ & $1.25(1.06,1.46)^{*}$ & $1.12(0.96,1.30)$ & $1.15(1.00,1.32)^{*}$ & $1.18(0.97,1.44)$ \\
\hline $9-10$ & $1.07(0.83,1.38)$ & $1.06(0.85,1.31)$ & $1.09(0.91,1.29)$ & $1.04(0.56,1.94)$ \\
\hline$\geq 10$ & $1.10(0.73,1.64)$ & $0.87(0.64,1.18)$ & $1.02(0.78,1.35)$ & $0.76(0.44,1.32)$ \\
\hline \multicolumn{5}{|c|}{ Weekend sleep duration(h) } \\
\hline 8-9(ref) & 1.00 & 1.00 & 1.00 & 1.00 \\
\hline$<6$ & $1.54(1.01,2.35)^{*}$ & $1.59(1.14,2.20)^{*}$ & $1.20(0.78,1.86)$ & $1.74(1.26,2.40)^{*}$ \\
\hline $6-7$ & $1.29(0.97,1.72)$ & $1.09(0.86,1.38)$ & $1.39(1.06,1.82)^{*}$ & $0.97(0.76,1.24)$ \\
\hline $7-8$ & $1.12(0.91,1.37)$ & $1.14(0.94,1.39)$ & $1.24(1.01,1.53)^{*}$ & $1.04(0.86,1.26)$ \\
\hline $9-10$ & $0.98(0.84,1.14)$ & $1.12(0.95,1.31)$ & $1.14(0.98,1.33)$ & $0.97(0.83,1.14)$ \\
\hline$\geq 10$ & $0.94(0.82,1.08)$ & $0.98(0.85,1.12)$ & $1.04(0.91,1.19)$ & $0.90(0.78,1.03)$ \\
\hline \multicolumn{5}{|c|}{ Weekend catch-up sleep } \\
\hline $0-1$ (ref) & 1.00 & 1.00 & 1.00 & 1.00 \\
\hline$<0$ & $1.29(0.97,1.72)$ & $1.49(1.20,1.85)^{* *}$ & $1.15(0.92,1.43)$ & $1.92(1.45,2.54)^{* *}$ \\
\hline $1-2$ & $0.96(0.79,1.17)$ & $1.08(0.90,1.30)$ & $0.89(0.75,1.06)$ & $1.24(1.01,1.52)^{*}$ \\
\hline $2-3$ & $1.10(0.91,1.32)$ & $1.11(0.94,1.32)$ & $1.02(0.86,1.20)$ & $1.24(1.02,1.51)^{*}$ \\
\hline$\geq 3$ & $0.97(0.81,1.17)$ & $1.20(1.01,1.42)^{*}$ & $1.06(0.89,1.26)$ & $1.15(0.95,1.38)$ \\
\hline
\end{tabular}

${ }^{*} P<0.05$, ** $P<0.001$; OR is odds ratios; Cl is confidence interval; NSSI is non-suicidal self-injury; Adjusted model controlled regional areas, sex, grade, only child, parents' education level, family economic status, sleep quality, psychological symptoms, weekday video time, weekend video time, weekday video game time, weekend video game time

This study expands our knowledge of the association between sleep duration and NSSI by examining sex and grade differences. We believe the present study is the first to show a U-shaped association between sleep duration and total NSSI number. Another major strength of this investigation was the large representative sample and age range studied, which included late childhood through adolescence. In addition, we considered a wide range of potential covariates, including sleep quality, psychological symptoms, and screen time. We believe this study provides key insights for the prevention of adolescent NSSI.

The present study had several limitations. First, this study was cross-sectional, thus causality cannot be inferred. However, most of the previous studies on NSSI used cross-sectional research [63, 64], and our findings pertaining to the association between sleep and NSSI were similar to those in previous cohort studies [54, 65, 66]. Further longitudinal studies are needed to replicate our findings and clarify the causality and mechanisms that relate to sleep duration, neuropsychiatric status, and NSSI. Second, selfreported NSSI is prone to recall bias and social desirability bias. For a majority of adolescents, self-harm remains a hidden act [67]. Investigations into NSSI are sensitive, and the reporting rate may be lower than the actual levels [68]. In addition, sleep duration data were obtained by self-report and were not verified by objective measures such as actigraphy (a measurement of the motor activity sensor) or polysomnography (sleep study) because it was a nationwide large-scale survey study. The collection of 

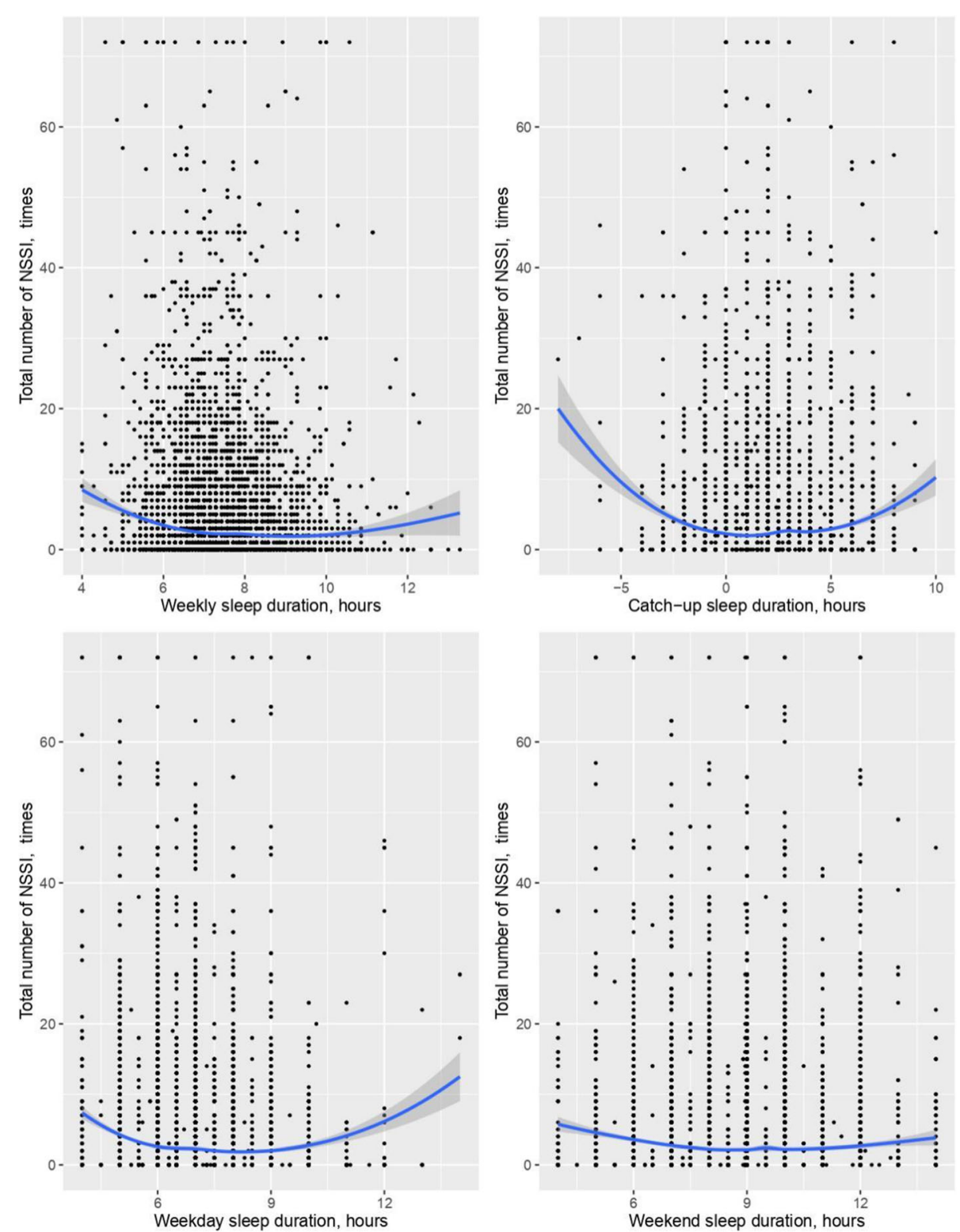

Fig. 1 Association between sleep duration and total NSSI number

objective sleep measures via physiologic monitoring is cost-prohibitive and often not feasible. Additionally, self-reported sleep duration may be an overestimation of the actual measured sleep duration [69, 70]. However, previous studies have shown good agreement between self-reported sleep durations and those obtained through actigraphic monitoring [69, 70]. Moreover, self-reported sleep duration is considered more accurate in detecting long-term sleep habits and more suitable for large-scale epidemiologic studies [71]. In the future, measurement of sleep duration using polysomnography or actigraphy may be recommended to explore the mechanism further. Third, while we investigated students' screen time in our study, we ignored students' social media use. This needs to be investigated more thoroughly in the near future. Fourth, the association between sleep duration and NSSI may be partly accounted for by other parameters such as childhood physical or sexual abuse. Future studies are needed to examine mediators and moderators between sleep duration and NSSI in adolescents, which would provide more clues on adolescent NSSI prevention. Lastly, studies with a larger sample size may have increased the generalizability of the results and powered to detect even small differences. However, statistically significant did not necessarily mean clinically significant, thus the clinical or practical implications of our findings should be studied further. 
Table 5 Binomial regression analysis of the effect of sleep duration on total NSSI number

\begin{tabular}{|c|c|c|c|c|c|c|}
\hline \multirow[t]{2}{*}{ Variables } & \multicolumn{6}{|l|}{ Total NSSI number } \\
\hline & Crude OR(95\%Cl) & $F$ & $P$ value & Adjusted $O R(95 \% \mathrm{Cl})$ & $F$ & $P$ value \\
\hline \multicolumn{7}{|l|}{ Total number of NSSI } \\
\hline Daily sleep (h) & $-4.01(-4.90,-3.12)^{* *}$ & 63.68 & $<0.001$ & $-2.76(-3.62,-1.91)^{* *}$ & 88.36 & $<0.001$ \\
\hline Daily sleep $(h)^{2}$ & $0.23(0.18,0.29)^{* *}$ & & & $0.17(0.11,0.22)^{* *}$ & & \\
\hline \multicolumn{7}{|l|}{ Total number of NSSI } \\
\hline Weekday sleep (h) & $-3.91(-4.58,-3.24)^{* *}$ & 86.48 & $<0.001$ & $-2.59(-3.25,-1.94)^{* *}$ & 89.48 & $<0.001$ \\
\hline Weekday sleep (h) ${ }^{2}$ & $0.24(0.20,0.29)^{* *}$ & & & $0.17(0.12,0.21)^{* *}$ & & \\
\hline \multicolumn{7}{|l|}{ Total number of NSSI } \\
\hline Weekend sleep (h) & $-2.14(-2.61,-1.67)^{* *}$ & 42.74 & $<0.001$ & $-1.14(-1.60,-0.69)^{* *}$ & 86.95 & $<0.001$ \\
\hline Weekend sleep (h) ${ }^{2}$ & $0.11(0.09,0.14)^{* *}$ & & & $0.06(0.03,0.08)^{* *}$ & & \\
\hline \multicolumn{7}{|l|}{ Total number of NSSI } \\
\hline catch-up sleep (h) & $-0.36(-0.47,-0.26)^{* *}$ & 52.88 & $<0.001$ & $-0.24(-0.34,-0.15)^{* *}$ & 87.36 & $<0.001$ \\
\hline catch-up sleep (h) ${ }^{2}$ & $0.10(0.08,0.12)^{* *}$ & & & $0.05(0.04,0.07)^{* *}$ & & \\
\hline
\end{tabular}

${ }^{*} P<0.05,{ }^{* *} P<0.001$; OR is odds ratios; $\mathrm{Cl}$ is confidence interval; NSSI is non-suicidal self-injury; Adjusted model controlled regional areas, sex, grade, registered residence, only child, parents' education level, family economic status, sleep quality, psychological symptoms, weekday video time, weekend video time, weekday video game time, weekend video game time

\section{Conclusion}

This study provides key insights into the association between sleep duration and NSSI among Chinese adolescents. Our findings show that excessive or restricted sleep duration is associated with an increased risk of NSSI. Parents, teachers, and child health workers are encouraged to be vigilant and screen for sleep problems in adolescents. Future research will determine if early intervention with sleep duration reduces the risk of NSSI in adolescents.

\section{Abbreviations}

NSSI: Non-Suicidal Self-Injury; ORs: Crude Odds Ratios; aOR: Adjusted Odd Ratio; Cl: Confidence Interval; SCN: Suprachiasmatic Nuclei; TNF-a: Tumor Necrosis Factor-alpha; IL-10: Interleukin 10; CRP: C-Reactive Protein; HPA: Hypothalamic-Pituitary-Adrenal; DMN: Default Mode Network; LOESS: Locally Estimated Scatterplot Smoothing; ADHD: Attention-Deficit Hyperactivity Disorder; MSQA: Multidimensional Sub-health Questionnaire of Adolescents

\section{Supplementary Information}

The online version contains supplementary material available at https://doi. org/10.1186/s12888-021-03539-x.

Additional file 1. English version and Chinese version of Chinese Adolescent Physical and Mental Health Monitoring Questionnaire.

\section{Acknowledgments}

We would like to acknowledge all school action teams, the staff and students from the participating schools, and our cooperators for assistance in data collection.

\section{Authors' contributions}

YT and YW worked on data analysis, developed the study design, reviewed the topic related literature and wrote the first draft of the manuscript. SX, SZ and $\mathrm{JH}$ performed data collection, coordination, and involved in interpretation of the data and revision of the manuscript. FT performed the study design and carried out study supervision and revision of the manuscript. All authors significantly contributed to the project, read and approved the final manuscript of the protocol.

\section{Funding}

Funding for the project was provided by National Natural Science Foundation of China $(81773453,81202223,82073578)$, Natural Science Foundation of Anhui province $(1708085 \mathrm{QH} 223)$. The funders had no role in study design, data collection and analysis, decision to publish, or preparation of the manuscript.

Availability of data and materials

The datasets that were generated analyzed for the current study are not publicly available as the author does not have permission to share the data.

\section{Declarations}

\section{Ethics approval and consent to participate}

The study was approved by the ethics committee of Anhui Medical University (2012534). Permission for the study was requested from schools, parents, and students before completion of the surveys. During the organization period, we got "written informed consent" from school principal of each school and head teacher of each class for this health questionnaire survey. The students were allowed to participate in the study upon receiving completed consent form from their parents. One week prior to screening day, the parents or guardians of the students were informed of the study through a notice sent home from the schools asking them to contact the teachers by phone if they wish their child to participate in the survey. Prior to the formal investigation, the team members explained the anonymous and confidential nature of the data to the students, and provided an opportunity for them to ask questions. If they were not willing to participate, they were allowed to withdraw from the study. Consent to participate in the study was recorded in a separate consent form with the questionnaire, and it was confirmed upon completion and return of the questionnaire.

\section{Consent for publication}

Not Applicable.

\section{Competing interests}

The authors declare no conflict of interest. 


\section{Author details}

'Department of Maternal, Child and Adolescent Health, School of Public Health, Anhui Medical University, No 81 Meishan Road, Hefei 230032, Anhui, China. ${ }^{2}$ MOE Key Laboratory of Population Health Across Life Cycle, No 81 Meishan Road, Hefei 230032, Anhui, China. ${ }^{3} \mathrm{NHC}$ Key Laboratory of Study on Abnormal Gametes and Reproductive Tract, No 81 Meishan Road, Hefei 230032, Anhui, China. ${ }^{4}$ Anhui Provincial Key Laboratory of Population Health and Aristogenics, Anhui Medical University; No 81 Meishan Road, Hefei 230032, Anhui, China.

Received: 4 October 2020 Accepted: 13 October 2021 Published online: 21 October 2021

\section{References}

1. Nock MK. Self-injury. Annu Rev Clin Psychol. 2010;6(1):339-63. https://doi. org/10.1146/annurev.clinpsy.121208.131258.

2. Swannell SV, Martin GE, Page A, Hasking P, St JN. Prevalence of nonsuicida self-injury in nonclinical samples: systematic review, meta-analysis and meta-regression. Suicide Life Threat Behav. 2014;44(3):273-303. https://doi. org/10.1111/sltb.12070.

3. Kiekens $G$, Hasking $P$, Claes L, Boyes M, Mortier P, Auerbach RP, et al Predicting the incidence of non-suicidal self-injury in college students. Eur Psychiatry. 2019;59:44-51. https://doi.org/10.1016/j.eurpsy.2019.04.002.

4. McManus S, Gunnell D, Cooper C, Bebbington PE, Howard LM, Brugha T, et al. Prevalence of non-suicidal self-harm and service contact in England, 2000-14: repeated cross-sectional surveys of the general population. Lancet Psychiat. 2019;6(7):573-81. https://doi.org/10.1016/S2215-0366(19)30188-9.

5. Zetterqvist $M$, Lundh L, Dahlström Ö, Svedin CG. Prevalence and function of non-suicidal self-injury (NSSI) in a community sample of adolescents, using suggested DSM-5 criteria for a potential NSSI disorder. J Abnorm Child Psych. 2013;41(5):759-73. https://doi.org/10.1007/s10802-013-9712-5.

6. Muehlenkamp JJ, Claes L, Havertape L, Plener PL. International prevalence of adolescent non-suicidal self-injury and deliberate self-harm. Child Adolesc Psychiatry Ment Health. 2012;6:10

7. Lang J, Yao Y. Prevalence of nonsuicidal self-injury in chinese middle school and high school students: a meta-analysis. Medicine (Baltimore). 2018;97(42): e12916. https://doi.org/10.1097/MD.0000000000012916.

8. Klonsky ED, May AM, Glenn CR. The relationship between nonsuicidal selfinjury and attempted suicide: converging evidence from four samples. J Abnorm Psychol. 2013;122(1):231-7. https://doi.org/10.1037/a0030278.

9. Ford ES, Cunningham TJ, Croft JB. Trends in self-reported sleep duration among US adults from 1985 to 2012. Sleep. 2015;38(5):829-32. https://doi. org/10.5665/sleep.4684.

10. Hirshkowitz M, Whiton K, Albert SM, Alessi C, Bruni O, DonCarlos L, et al. National Sleep Foundation's sleep time duration recommendations: methodology and results summary. Sleep Heal. 2015;1(1):40-3. https://doi. org/10.1016/j.sleh.2014.12.010.

11. Galland BC, Taylor BJ, Elder DE, Herbison P. Normal sleep patterns in infants and children: a systematic review of observational studies. Sleep Med Rev. 2012;16(3):213-22. https://doi.org/10.1016/j.smrv.2011.06.001.

12. Paruthi S, Brooks L, D'Ambrosio C, Hall WA, Kotagal S, Lloyd RM, et al. Recommended amount of sleep for pediatric populations: a consensus statement of the American Academy of sleep medicine. J Clin Sleep Med. 2016:12(6):785-6. https://doi.org/10.5664/jcsm.5866.

13. Kang V, Shao J, Zhang K, Mulvey M, Ming X, Wagner GC. Sleep deficiency and sleep health problems in chinese adolescents. Clin Med Insights Pediatr. 2012;6:11-7. https://doi.org/10.4137/CMPed.S8407.

14. Chen T, Wu Z, Shen Z, Zhang J, Shen X, Li S. Sleep duration in Chinese adolescents: biological, environmental, and behavioral predictors. Sleep Med. 2014:15(11):1345-53. https://doi.org/10.1016/j.sleep.2014.05.018.

15. Lebourgeois M, Giannotti F, Cortesi F, Wolfson A, Harsh J. The relationship between reported sleep quality and sleep hygiene in Italian and American adolescents. Pediatrics. 2005;115(Suppl 1):257-65. https://doi.org/10.1542/ peds.2004-0815 H.

16. Carskadon MA, Tarokh L. Developmental changes in sleep biology and potential effects on adolescent behavior and caffeine use. Nutr Rev. 2014; 72(Suppl 1):60-4. https://doi.org/10.1111/nure.12147.

17. Carissimi A, Dresch F, Martins AC, Levandovski RM, Adan A, Natale V, et al. The influence of school time on sleep patterns of children and adolescents. Sleep Med. 2016;19:33-9. https://doi.org/10.1016/j.sleep.2015.09.024.
18. Short MA, Gradisar M, Wright H, Lack LC, Dohnt H, Carskadon MA. Time for bed: parent-set bedtimes associated with improved sleep and daytime functioning in adolescents. Sleep. 2011;34(6):797-800. https://doi.org/10. 5665/SLEEP.1052

19. Bartel KA, Gradisar M, Williamson P. Protective and risk factors for adolescent sleep: a meta-analytic review. Sleep Med Rev. 2015;21:72-85. https://doi.org/10.1016/j.smrv.2014.08.002.

20. Gradisar M, Gardner G, Dohnt H. Recent worldwide sleep patterns and problems during adolescence: a review and meta-analysis of age, region, and sleep. Sleep Med. 2011;12(2):110-8. https://doi.org/10.1016/j.sleep.201 0.11 .008 .

21. Dorofaeff TF, Denny S. Sleep and adolescence. Do New Zealand teenagers get enough? J Paediatr Child Health. 2006;42(9):515-20. https://doi.org/1 0.1111/j.1440-1754.2006.00914.x.

22. Lee B, Kang S, Choi J, Lee Y. The association between self-reported sleep duration and body mass index among Korean adolescents. J Korean Med Sci. 2016;31(12):1996-2001. https://doi.org/10.3346/jkms.2016.31.12.1996.

23. Chung KF, Cheung MM. Sleep-wake patterns and sleep disturbance among Hong Kong Chinese adolescents. Sleep. 2008;31(2):185-94. https://doi.org/1 0.1093/sleep/31.2.185.

24. Carskadon MA, Wolfson AR, Acebo C, Tzischinsky O, Seifer R. Adolescent sleep patterns, circadian timing, and sleepiness at a transition to early school days. Sleep. 1998;21(8):871-81. https://doi.org/10.1093/sleep/21.8.871.

25. Wittmann M, Dinich J, Merrow M, Roenneberg T. Social jetlag: misalignment of biological and social time. Chronobiol Int. 2006;23(1-2):497-509. https:// doi.org/10.1080/07420520500545979.

26. Owens J. Insufficient sleep in adolescents and young adults: an update on causes and consequences. Pediatrics. 2014;134(3):e921-32. https://doi.org/1 0.1542/peds.2014-1696.

27. Lundh L, Bjärehed J, Wångby-Lundh M. Poor sleep as a risk factor for nonsuicidal self-injury in adolescent girls. J Psychopathol Behav Assess. 2013:35(1):85-92. https://doi.org/10.1007/s10862-012-9307-4.

28. Hysing M, Sivertsen B, Stormark KM, O'Connor RC. Sleep problems and selfharm in adolescence. Brit J Psychiat. 2015;207(4):306-12. https://doi.org/1 0.1192/bjp.bp.114.146514.

29. Liu X, Chen H, Bo QG, Fan F, Jia CX. Poor sleep quality and nightmares are associated with non-suicidal self-injury in adolescents. Eur Child Adoles Psy. 2016:26(3):1-9.

30. Russell K, Allan S, Beattie L, Bohan J, MacMahon K, Rasmussen S. Sleep problem, suicide and self-harm in university students: a systematic review. Sleep Med Rev. 2019;44:58-69. https://doi.org/10.1016/j.smrv.2018.12.008.

31. Wan Y, Xu S, Chen J, Hu C, Tao F. Longitudinal effects of psychological symptoms on non-suicidal self-injury: a difference between adolescents and young adults in China. Soc Psychiatry Psychiatr Epidemiol. 2015;50(2):23747. https://doi.org/10.1007/s00127-014-0917-x.

32. Baiden $P$, Tadeo SK, Peters KE. The association between excessive screentime behaviors and insufficient sleep among adolescents: findings from the 2017 youth risk behavior surveillance system. Psychiatry Res. 2019;281 112586. https://doi.org/10.1016/j.psychres.2019.112586.

33. Baiden P, Tadeo SK, Tonui BC, Seastrunk JD, Boateng GO. Association between insufficient sleep and suicidal ideation among adolescents. Psychiatry Res. 2020;287:112579. https://doi.org/10.1016/j.psychres.2019.112579.

34. Mars B, Heron J, Klonsky ED, Moran P, O'Connor RC, Tilling K, et al. Predictors of future suicide attempt among adolescents with suicidal thoughts or non-suicidal self-harm: a population-based birth cohort study. Lancet Psychiat. 2019;6(4):327-37. https://doi.org/10.1016/S2215-0366(19)3 0030-6.

35. Wan Y, Xu H, Wang S, Boyda D, Mcfeeters D, Sun Y, et al. Gender differences in the relationship between sleep problems and suicide attempt in adolescents. Front Psychiatry. 2020;11:133. https://doi.org/10.3389/fpsyt.2 020.00133 .

36. Tao FB, Hu CL, Sun YH, Hao JH. The development and application of multidimensional sub-health questionnaire of adolescents (MSQA). Chin J Dis Control Prev. 2008;12:309-13 (in Chinese with English abstract).

37. Xing C, Tao FB, Yuan CJ, Wan YH, Qi XY, Hu CL, et al. Evaluation of reliability and validity of the multidimensional sub-health questionnaire of adolescents. Chin J Public Health. 2008;24:1031-3 (in Chinese with English abstract).

38. Centers for disease Control and Prevention Adolescent and School Health. YRBSS Questionnaire. CDC. 2013:2013 https://www.cdc.gov/healthyyouth/da ta/yrbs/questionnaires.htm. 
39. Hagenauer MH, Perryman Jl, Lee TM, Carskadon MA. Adolescent changes in the homeostatic and circadian regulation of sleep. Dev Neurosci. 2009;31(4): 276-84. https://doi.org/10.1159/000216538.

40. Bonmati-Carrion MA, Baño-Otalora B, Madrid JA, Rol MA. Light color importance for circadian entrainment in a diurnal (Octodon degus) and a nocturnal (Rattus norvegicus) rodent. Sci Rep. 2017;7(1):8846. https://doi. org/10.1038/s41598-017-08691-7.

41. Ehlen JC, Jefferson F, Brager AJ, Benveniste M, Paul KN. Period-amplitude analysis reveals wake-dependent changes in the electroencephalogram during sleep deprivation. Sleep. 2013;36(11):1723-35. https://doi.org/10. 5665/sleep.3138.

42. Crowley SJ, Cain SW, Burns AC, Acebo C, Carskadon MA. Increased sensitivity of the circadian system to light in early/mid-puberty. J Clin Endocrinol Metab. 2015;100(11):4067-73. https://doi.org/10.1210/jc.2015-2 775.

43. Vernon L, Modecki K, Barber B. Mobile phones in the bedroom: trajectories of sleep habits and subsequent adolescent psychosocial development. Child Dev. 2017;89(1):66-77. https://doi.org/10.1111/cdev.12836.

44. Buzek T, Poulain T, Vogel M, Engel C, Bussler S, Körner A, et al. Relations between sleep duration with overweight and academic stress - just a matter of the socioeconomic status? Sleep Heal. 2019:5(2):208-15. https:// doi.org/10.1016/j.sleh.2018.12.004.

45. Lo JC, Lee SM, Lee XK, Sasmita K, Chee NIYN, Tandi J, et al. Sustained benefits of delaying school start time on adolescent sleep and well-being. Sleep. 2018;41(6):52.

46. Agathão BT, Lopes CS, Cunha DB, Sichieri R. Gender differences in the impact of sleep duration on common mental disorders in school students. BMC Public Health. 2020;20(1):148. https://doi.org/10.1186/s12889-020-82605.

47. Yeo SC, Jos AM, Erwin C, Lee SM, Lee XK, Lo JC, et al. Associations of sleep duration on school nights with self-rated health, overweight, and depression symptoms in adolescents: problems and possible solutions. Sleep Med. 2019;60:96-108. https://doi.org/10.1016/j.sleep.2018.10.041.

48. Lewin DS, Wang G, Chen YI, Skora E, Hoehn J, Baylor A, et al. Variable school start times and middle school student's sleep health and academic performance. J Adolesc Health. 2017;61(2):205-11. https://doi.org/10.1016/j. jadohealth.2017.02.017.

49. Lin P, Lin C, Wang P, Yang S. Association between sleeping duration and health-related behaviors in college student. Social Health and Behavior. 2018;1(1):31-6.

50. Lehto JE, Aho O, Eklund $M$, Heinaro $M$, Kettunen S, Peltomäki A, et al. Circadian preferences and sleep in 15- to 20-year old Finnish students. Sleep Sci. 2016;9(2):78-83. https://doi.org/10.1016/j.slsci.2016.06.003.

51. Franco P, Putois B, Guyon A, Raoux A, Papadopoulou M, Guignard-Perret A, et al. Sleep during development: sex and gender differences. Sleep Med Rev. 2020;51:101276. https://doi.org/10.1016/j.smrv.2020.101276.

52. Hoyt LT, Deardorff J, Marceau K, Laurent CA, Windham GC, Greenspan LC, et al. Girls' sleep trajectories across the pubertal transition: emerging racial/ ethnic differences. J Adolesc Health. 2018;62(4):496-503. https://doi.org/10.1 016/j.jadohealth.2017.10.014.

53. Crowley SJ, Wolfson AR, Tarokh L, Carskadon MA. An update on adolescent sleep: new evidence informing the perfect storm model. J Adolesc. 2018;67: 55-65. https://doi.org/10.1016/j.adolescence.2018.06.001.

54. Junker A, Bjørngaard JH, Gunnell D, Bjerkeset O. Sleep problems and hospitalization for self-harm: a 15-year follow-up of 9,000 Norwegian adolescents. The Young-HUNT Study Sleep. 2014;37(3):579-85.

55. McGlinchey EL, Courtney-Seidler EA, German M, Miller AL. The role of sleep disturbance in suicidal and nonsuicidal self-injurious behavior among adolescents. Suicide Life Threat Behav. 2017;47(1):103-11. https://doi.org/1 $0.1111 /$ sltb.12268.

56. Irwin MR, Olmstead R, Carroll JE. Sleep disturbance, sleep duration, and inflammation: a systematic review and Meta-analysis of cohort studies and experimental sleep deprivation. Biol Psychiatry. 2016;80(1):40-52. https://doi. org/10.1016/j.biopsych.2015.05.014

57. Wright KP, Drake AL, Frey DJ, Fleshner M, Desouza CA, Gronfier C, et al. Influence of sleep deprivation and circadian misalignment on cortisol, inflammatory markers, and cytokine balance. Brain Behav Immun. 2015;47: 24-34. https://doi.org/10.1016/j.bbi.2015.01.004.

58. Kim JS, Kang E, Bahk YC, Jang S, Hong KS, Baek JH. Exploratory analysis of behavioral impulsivity, pro-inflammatory cytokines, and resting-state frontal EEG activity associated with non-suicidal self-injury in patients with mood disorder. Front Psychiatry. 2020;11:124. https://doi.org/10.3389/fpsyt.2020. 00124.

59. Reichl C, Heyer A, Brunner R, Parzer P, Völker JM, Resch F, et al. Hypothalamic-pituitary-adrenal axis, childhood adversity and adolescent nonsuicidal self-injury. Psychoneuroendocrino. 2016;74:203-11. https://doi. org/10.1016/j.psyneuen.2016.09.011.

60. Kaess M, Hille M, Parzer P, Maser-Gluth C, Resch F, Brunner R. Alterations in the neuroendocrinological stress response to acute psychosocial stress in adolescents engaging in nonsuicidal self-injury. Psychoneuroendocrino. 2012;37(1):157-61. https://doi.org/10.1016/j.psyneuen.2011.05.009.

61. Lunsford-Avery JR, Damme KSF, Engelhard MM, Kollins SH, Mittal VA. Sleep/ wake regularity associated with default mode network structure among healthy adolescents and young adults. Sci Rep. 2020;10(1):509. https://doi. org/10.1038/s41598-019-57024-3.

62. Mohan A, Roberto A, Lorenzo A, Jones K, Carney M, Liogier-Weyback L, et al. The significance of the default mode network (DMN) in neurological and neuropsychiatric disorders: a review. Yale J Biol Med. 2016;89(1):49-57.

63. Boduszek D, Debowska A, Ochen EA, Fray C, Nanfuka EK, Powell-Booth K, et al. Prevalence and correlates of non-suicidal self-injury, suicidal ideation, and suicide attempt among children and adolescents: findings from Uganda and Jamaica. J Affect Disord. 2021;283:172-8. https://doi.org/10.101 6/j.jad.2021.01.063.

64. Wan Y, Chen R, Ma S, McFeeters D, Sun Y, Hao J, et al. Associations of adverse childhood experiences and social support with self-injurious behaviour and suicidality in adolescents. Brit J Psychiat. 2019;214(3):146-52. https://doi.org/10.1192/bjp.2018.263.

65. Wong MM, Brower KJ, Zucker RA. Sleep problems, suicidal ideation, and self-harm behaviors in adolescence. J Psychiatr Res. 2011;45(4):505-11. https://doi.org/10.1016/j.jpsychires.2010.09.005.

66. Asarnow JR, Bai S, Babeva KN, Adrian M, Berk MS, Asarnow LD, et al. Sleep in youth with repeated self-harm and high suicidality: does sleep predict self-harm risk? Suicide Life Threat Behav. 2020;50(6):1189-97. https://doi. org/10.1111/sltb.12658.

67. Doyle L, Treacy MP, Sheridan A. Self-harm in young people: prevalence, associated factors, and help-seeking in school-going adolescents. Int J Ment Health Nurs. 2015;24(6):485-94. https://doi.org/10.1111/inm.12144.

68. Wang S, Xu H, Zhang S, Wan Y, Tao F. Mediating effects of self-esteem in the relationship between childhood maltreatment and non-suicidal selfinjury among adolescents: the roles of sex and only-child status. Soc Sci Med. 2020;249:112847.

69. Lockley SW, Skene DJ, Arendt J. Comparison between subjective and actigraphic measurement of sleep and sleep rhythms. J Sleep Res. 1999;8(3): 175-83. https://doi.org/10.1046/j.1365-2869.1999.00155.x.

70. Cespedes EM, Hu FB, Redline S, Rosner B, Alcantara C, Cai J, et al. Comparison of self-reported sleep duration with Actigraphy: results from the Hispanic community health study/study of Latinos Sueno ancillary study. Am J Epidemiol. 2016;183(6):561-73. https://doi.org/10.1093/aje/kwv2 51.

71. Kim JW, Jung HJ, Choi HG, Rhee CS, Wee JH. Association between sleep duration and chronic rhinosinusitis among the Korean general adult population: Korea National Health and nutrition examination survey. Sci Rep. 2019;9(1):7158. https://doi.org/10.1038/s41598-019-43585-w.

\section{Publisher's Note}

Springer Nature remains neutral with regard to jurisdictional claims in published maps and institutional affiliations.

Ready to submit your research? Choose BMC and benefit from:

- fast, convenient online submission

- thorough peer review by experienced researchers in your field

- rapid publication on acceptance

- support for research data, including large and complex data types

- gold Open Access which fosters wider collaboration and increased citations

- maximum visibility for your research: over $100 \mathrm{M}$ website views per year

At BMC, research is always in progress.

Learn more biomedcentral.com/submissions 